\title{
SISTEM INFORMASI DESA BERBASIS WEB (STUDI KASUS DESA WEDING)
}

\author{
Zaenal Mustofa ${ }^{1}$, Mokhamad Iklil Mustofa ${ }^{2}$ \\ ${ }^{1,2}$ Program Studi Sistem Komputer Sekolah Tinggi Elektronika dan Komputer Pat, Semarang \\ zaenal@stekom.ac.id, $\underline{\text { 2iklil@stekom.ac.id }}$
}

\begin{abstract}
The rapid development of technology, especially the internet which is followed by the movement/mobilization of the community in fulfilling the needs of life and education, as well as public awareness of the needs of village administrative requirements, such as family cards, identity cards, birth certificates, land ownership certificates, data collection of the final voters list and other village administrations, so that the village apparatus must be extra in carrying out data collection on the village in an integrated manner, so that it can be accessed anywhere via an internet connection without returning to their hometown. The village apparatus can classify the conditions of the community with certain categories using this system, such as education and welfare. Villagers who migrate outside the island want to make birth certificates, renew e-ID cards, family cards, etc., do not need to go back to their hometowns, just send physical files and scan files that are expected to the "Village Web Information System" application to request the documents. Furthermore, if there is a presidential election, then the parties registered with DPT can ask information through the info menu facility available in this system, so that election file files can be sent to the address of villagers who migrate outside the island / city to be able to use their voting rights. All village data will be recorded / records related to the current domicile, such as education, employment, birth certificate, e-ID card, ownership of land certificates, payment of land and building taxes, and other village administration completeness.
\end{abstract}

Keywords: village information system, web, villagers, internet, data access, village administration system, population dispersion

\section{Pendahuluan}

Berkembangnya teknologi secara pesat terutama internet memiliki banyak manfaat untuk kehidupan masyarakat. Perpindahan/mobilisasi masyarakat dalam memenuhi kebutuhan hidup dan pendidikan (berdomisili sementara di luar kota), serta kesadaran masyarakat terhadap kebutuhan persyaratan administrasi desa, seperti kartu keluarga, kartu tanda penduduk, akta kelahiran, surat kepemilikan tanah, pendataan daftar pemilih tetap (DPT) dan administrasi desa lainnya mengharuskan mereka yang hidup dalam perantauan harus pulang dengan biaya yang tidak sedikit karena menangung biaya transportasi, biaya perjalanan lainnya dan terbatasi oleh waktu, seperti waktu libur kerja atau waktu libur kuliah.

Sistem informasi yang menggunakan teknologi web mobile yang membuat semua informasi dapat diakses melalu smartphone dengan koneksi internet, sehingga yang selama ini pengurusan administrasi desa harus datiag langsung dan banyak menggunakan bukti fisik, dengan sistem ini hanya menggunakan file-file digital yang dapat ditransaksikan melalui internet dan web mobile (Novianti dkk., 2014) tanpa datang ke kantor desa langsung (Rotikan dan Tamboto, 2016). Konsep E-Government merupakan konsep agenda reformasi untuk menciptakan pemerintahan yang bagus (good governance) dalam upaya untuk meningkatkan pelayanan semua instansi pemerintahan terhadap masyarakat yang terdiri adanya transparansi, akuntabilitas, efisiensi, dan partisipasi masyarakat terhadap kebijakan publik (Effendi, 2009).

Masyarakat desa yang merantau di luar pulau ingin membuat akta kelahiran, memperbarui ektp, kartu keluarga, dan lain sebagainya, tidak perlu pulang ke kampung halaman, cukup kirim fisik dan file scan berkas-berkas yang diharapkan ke aplikasi "Sistem Informasi Web Desa" untuk mohon diuruskan surat-surat tersebut. Selanjtunya jika terjadi adanya pemilu presiden, maka pihak yang terdaftar DPT dapat 
melakukan tanya informasi lewat fasilitas menu info yang tersedia di sistem ini, sehingga berkas berkas pemilu dapat dikirim ke alamat warga desa yang merantau di luar pulau/kota untuk dapat digunakan hak pilihnya. Semua data warga desa akan direkam/record yang berkaitan dengan domisili saat ini, seperti pendidikan, pekerjaan, akta kelahiran, e-ktp, kepemilikan surat tanah, pembayaran pajak bumi dan bangunan, dan kelengkapan administrasi desa lainnya.

Aplikasi web populer akhir - akhir ini, karena menyediakan kemudahan dalam melakukan akses informasi melalui sistem informasi yang di-online-kan dan dapat diakses dimanapun melalui komputer dekstop, laptop, maupun smartphone yang terkoneksi jaringan internet. Sistem informasi berbasis web juga merupakan web application yang dibuat melalui IDE Application (Aplikasi untuk mengetikkan coding webnya) dengan menggunakan bahasa pemrograman tertentu yang mendukung web application, seperti PHP, JAVA, HTML, XML, dan dikolaborasikan dengan database MYSQL yang merupakan free license database.

Sumber daya manusia, infrastruktur, dan organisasi merupakan tantangan yang akan dihadapi dalam penyusunan sistem ini. Faktor lainnya yang juga berpengaruh adalah kurangnya koordinasi, lemahnya pengaturan, lemahnya kepemimpinan, dan kesenjangan wawasan dunia digital (Dien, 2014).

\section{Kerangka Teori}

\subsection{Sistem Informasi Desa}

Sistem informasi merupakan suatu sistem yang digunakan untuk mendukung fungsi operasi organisasi, sehingga dapat menyediakan informasi dari hasil beberapa data yang diolah dengan metode tertentu kepada pihak internal maupun external dengan laporan-laporan yang disajikan (Jogiyanto, 2003). Sistem informasi desa merupakan sistem informasi yang digunakan untuk mendukung pelayanan informasi yang ditujukan pada masyarakat desa yang berasaskan akuntabilitas, efisiensi, transparansi, dan komunikatif.

Desa adalah kesatuan masyarakat hukum yang memiliki batas wilayah yang berwenang untuk mengatur dan mengurus urusan pemerintahan, kepentingan masyarakat setempat berdasarkan prakarsa masyarakat, hak asal usul, dan/atau hak tradisional yang diakui dan dihormati dalam sistem pemerintahan Negara
Kesatuan Republik Indonesia (Undanng-undang No.6, 2014).

Web merupakan kumpulan dari berbagai macam halaman situs, yang terangkum didalam sebuah domain atau juga subdomain, yang lebih tempatnya berada di dalam WWW (World Wide $W e b)$.

\subsection{Metode Fuzzy Logic}

Menteri Perencanaan Pembangunan Nasional (PPN) Bambang Bojonegoro mengatakan, sejak September 2016, penghasilan penduduk yang menjadi batas garis kemiskinan yakni $\mathrm{Rp}$ 361.990 per kapita per bulan (https://ekonomi.kompas.com/read/2017/07/06/ 183640226/berapa.penghasilan.yang.masuk.kat egori.miskin.di.indonesia). Dari info tersebut peneliti membuat range kesejahteraan warga dengan metode fuzzy logic. Fuzzy Logic secara umum bisa diartikan sebuah metodologi berhitung denganvariabel kata-kata (linguistic variable) (Naba, 2009).

\section{Metodologi}

\subsection{Metode Penelitian}

Dalam penelitian ini metode yang digunakan untuk mengelompokkan hasil dari data-data yang sudah diolah menggunakan metode fuzzy logic yang merupakan bagian dari metode berbasis aturan/rulebase. Peneliti menggunakan metode ini karena metode ini fleksibel terhadap data-data yang akan dikelompokkan berdasarkan standar yang sesuai lapangan dimana standar tersebut hanya bisa ditentukan berdasarkan kesepakatan terhadap hasil pengolahan. Fuzzy dapat digunakan untuk mencari alternatif optimal dari sejumlah alternatif dengan kriteria tertentu, sehingga hal ini cocok untuk penyelesaian dalam penelitian ini. Adapun metode fuzzy logic dalam penentuan kesejahteraan warga desa merujuk pernyataan Menteri Perencanaan Pembangunan Nasional (PPN) Bambang Bojonegoro dan hasil observasi, sebagai berikut.

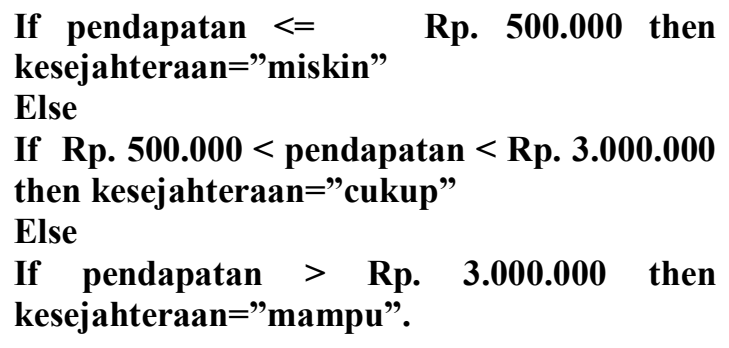




\subsection{Prosedur Penelitian}

Bagian ini memuat langkah-langkah peneliti dalam melakukan penelitian, disajikan secara lengkap namun padat. Kalau melakukan pendataan harus dijelaskan mulai dari metoda pengambilan sampel sampai dengan teknik analisis.

\section{a. Tahapan Studi Pustaka}

Pada tahapan ini dilakukan pengumpulan jurnal dan buku untuk mendapatkan pengetahuan yang mendukung pendelitian.

\section{b. Tahapan Identifikasi}

Pada tahapan ini melakukan observasi langsung di objek penelitian untuk mendapatkan permasalahan yang ada dan data-data yang akurat dan kredibel untuk menentukan perancangan sistem.

\section{c. Tahapan Perancangan Sistem}

Pada tahapan ini dirancangan suatu gambaran umum alur berjalannya system yang akan dibuat berdasarkan pada masalah yang ditemukan di lapangan.

\section{d. Tahapan Implementasi dan Simulasi}

Pada tahapan ini system yang sudah jadi kita terapkan dan kita simulasikan dengan beberapa data sampel yang ada.

\section{e. Tahapan Hasil dan Analisis}

Tahapan terakhir ini harus dilakukan setelah tahapan implementasi untuk mengetahui hasil yang didapat apa sudah sesuai kebutuhan atau belum sehingga dapat dianalisis apa kekurangan yang terjadi dan selanjutnya diperbaiki dan diterapkan dengan keadaan sebenarnya.

\section{Hasil dan Pembahasan}

\subsection{Hasil Kerangka Sistem Informasi Desa}

Kerangka Sistem Informasi Desa Berbasis Web ditunjukkan Tabel 4.1. Adapun masukkan, proses, dan keluaran dijabarkan sebagai berikut.

a. Masukkan

Pada tahapan ini admin menginputkan data warga desa weding sesuai yang ada di kerangka sistem.

b. Proses

Selanjutnya di tahap proses, admin mengolah data yang sudah masuk tersebut sesuai dengan klasifikasi yang ditentukan, salah satunya penentuan kesejahteraan warga menggunakan metode fuzzy logic.

c. Keluaran

Tahapan ini menghasilkan keluaran berupa: Diagram/grafik yang dapat dengan mudah dibaca berdasarkan hasil proses yang sudah diolah.

Tabel. 4.1 Kerangka Sistem Informasi Desa Berbasis Web

\begin{tabular}{|c|c|c|}
\hline Masukkan & Proses & Keluaran \\
\hline $\begin{array}{l}\text { Data Warga } \\
\text { Desa Weding: } \\
\text { 1. Berdasaria } \\
\text { n yang } \\
\text { tertera } \\
\text { dalam } \\
\text { KK/Kartu } \\
\text { Keluarga } \\
\text { Data } \\
\text { Warga } \\
\text { yang } \\
\text { merantau } \\
\text { kerja } \\
\text { Data yang } \\
\text { belum } \\
\text { lengkap } \\
\text { administras } \\
\text { i } \\
\text { Data } \\
\text { Kesejahter } \\
\text { aan }\end{array}$ & 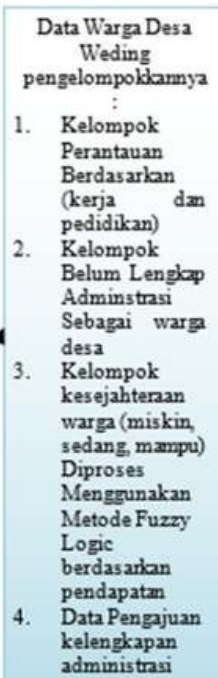 & $\begin{array}{l}\text { Dasbordhasil } \\
\text { pengolahandata: } \\
\text { 1. Monitoring } \\
\text { Administrasi } \\
\text { Kewargades } \\
\text { aan } \\
\text { (Pemecahan } \\
\text { KK, Akta } \\
\text { kelahiran, } \\
\text { akta tanah, } \\
\text { KTP, dII). } \\
\text { 2. Monitoring } \\
\text { kesejahtera } \\
\text { n warga } \\
\text { (mampu, } \\
\text { sedang, } \\
\text { miskin) } \\
\text { 3. Monitoring } \\
\text { Penyebaran } \\
\text { Warga }\end{array}$ \\
\hline
\end{tabular}

\subsection{Kerangka Konseptual Aplikasi}

Kerangka konseptual aplikasi dapat ditunjukkan Gambar 4.1 dan dipahami dengan penjabaran sebagai berikut:

a. Administrator

Administrator merupakan user dengan kekuaasaan lengkap, tambah, edit, hapus, dan semua laporan.

b. Admin

Admin merupakan user dengan kekuasaan dibatasi, seperti tambah, edit, dan sebagian laporan yang ditentukan oleh administrator.

c. Masyarakat

Masyarakat adalah user yang hanya menikmati menu luar dari system informasi dan tidak dapat masuk sebagai operator, seperti administrator dan admin. 


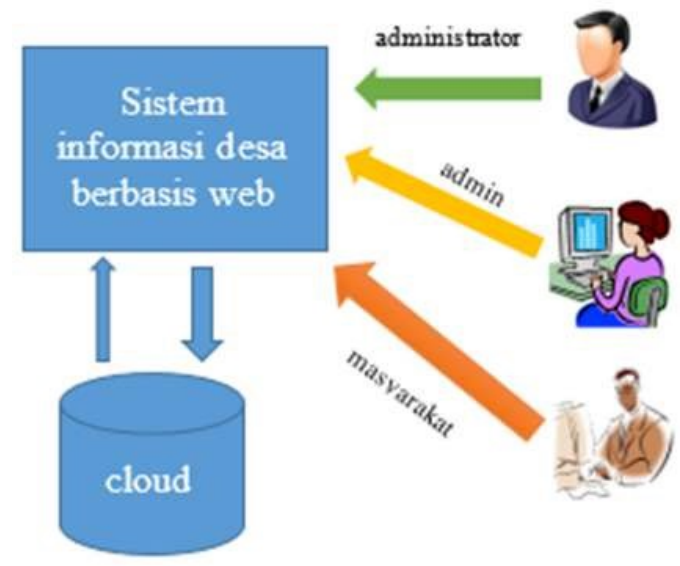

Gambar 4.1. Kerangka Konsep Aplikasi

\subsection{Pembahasan}

Penelitian dilakukan dengan menggunakan data warga weding sebanyak 5.734 warga.

a. Hasil penelitian jumlah yang memiliki KTP sebanyak 5.734 ini artinya data ini merupakan data yang siap digunakan sebagai DPT ditunjukkan Gambar 4.2.

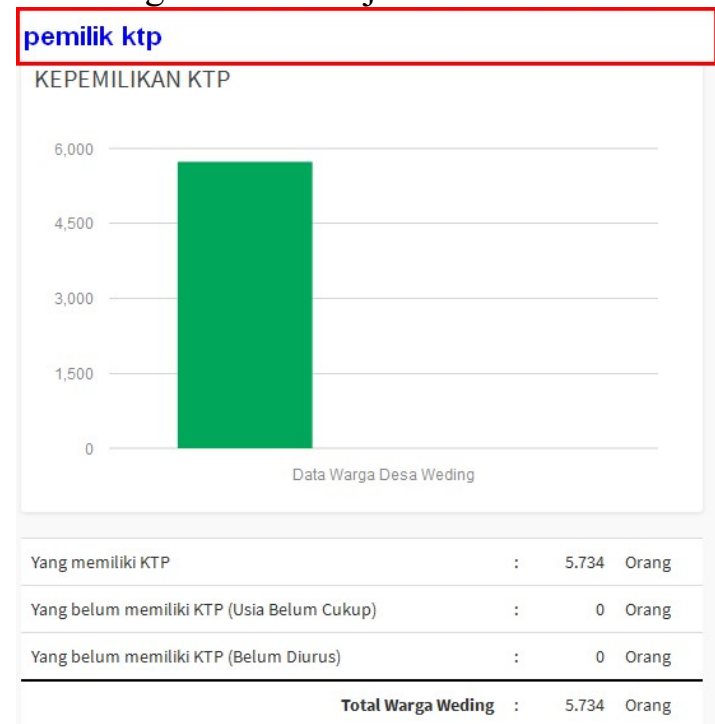

Gambar 4.2. Diagaram Pemilik KTP

b. Hasil dari pekerjaan warga weding Yang terdata memilik pekerjaan swasta 706 orang, dan wiraswasta 330, sisanya belum teregistrasi ditunjukkan Gambar 4.3

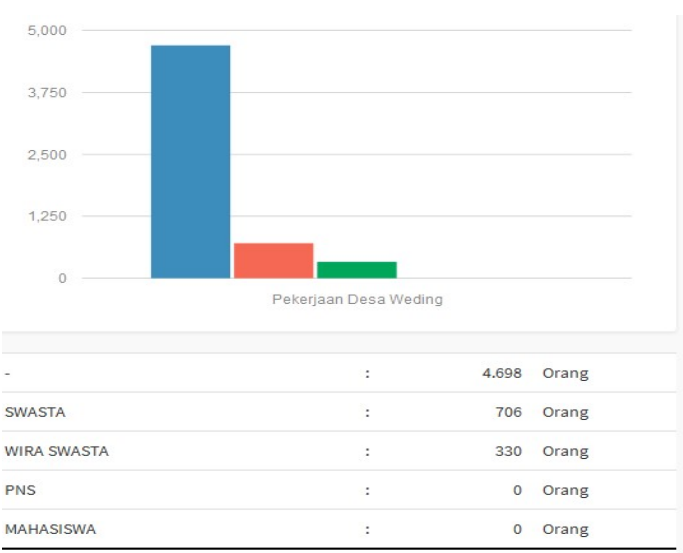

Gambar 4.3. Diagaram Pekerjaan yang teregistrasi

c. Hasil sampai akhir penelitian data kesejahteraan warga yang teregistrasi dalam perkalian 100, ditunjukkan Gambar 4.4.

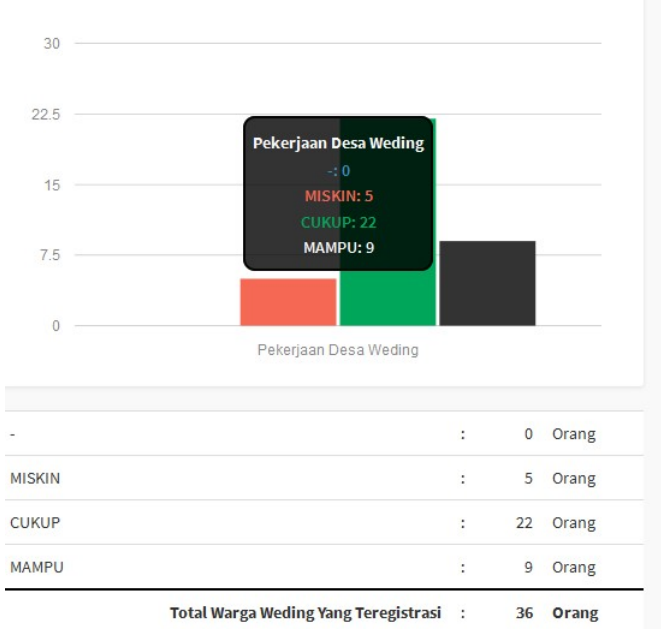

Gambar 4.4. Diagaram Kesejahteraan yang teregistrasi

\footnotetext{
If pendapatan $<=\quad$ Rp. 500.000 then kesejahteraan="miskin"

Else

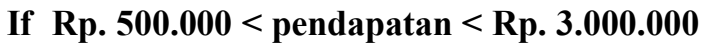
then kesejahteraan="cukup"

Else

If pendapatan $>$ Rp. 3.000 .000 then kesejahteraan="mampu".
} 
d. Hasil sampai akhir penelitian data pendidikan warga yang teregistrasi ditunjukkan Gambar 4.5.

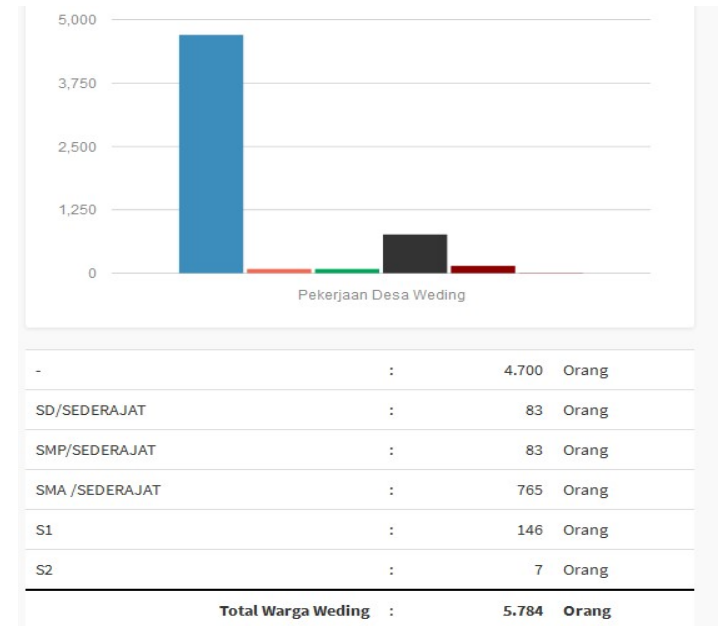

Gambar 4.5. Diagaram Pendidikan Warga yang teregistrasi

e. Hasil kepemilikan surat penting pada akhir pnelitian yang sudah teregistrasi ditunjukkan Gambar 4.6.

\begin{tabular}{|c|c|c|c|}
\hline NKK $\quad$ - seont. & a & & OTamban bar \\
\hline है MiK & Nama Warga & Alamat & Tahun Input \\
\hline 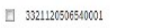 & ANSHORULLOH,H & wever & 2018 \\
\hline (1) 3321123005850003 & WUSTAKHD & ENer & 2018 \\
\hline D. 3321.2477595770001 & MUNAOZZROH & BENGR & 2016 \\
\hline D. 3321.25010780003 & AFFFH & Bever & 2018 \\
\hline 口.3321.250706200099 & TOMmBatur Rоникан & bever & 2018 \\
\hline 口. 33211257006820099 & тотвватия вониан & BEVER & 2018 \\
\hline घ 3321127112450006 & MASTUKAнA & BENER & 2018 \\
\hline 口 33211271121250006 & NASTUKAH & BENER & 2018 \\
\hline
\end{tabular}

Gambar 4.6. Diagaram kepemilikan surat penting Warga yang teregistrasi.

f. Hasil surat menyurat yang dilakukan oleh warga melalui sistem ditunjukkan Gambar 4.7. status tersebut memiliki keterangan selesai karena prosesnya sudah dlaksanakan oleh pegawai kelurahan.

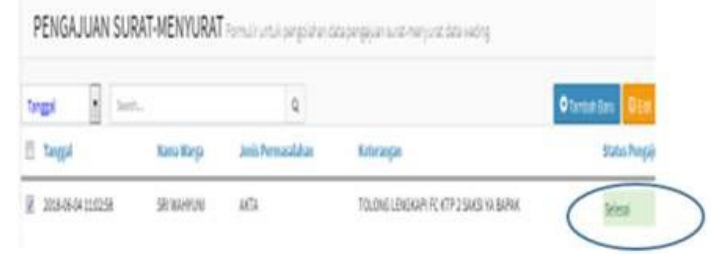

Gambar 4.7. Daftar Ajuan Warga yang teregistrasi melalui sistem informasi desa berbasis web.

\section{Kesimpulan}

Dengan penggunaan sistem informasi desa berbasis web ini pemerintah desa dan masyarakat dapat saling memanfaatkan data untuk kepentingan bersama, sehingga lebih tertata dan mudah dicari. Untuk situs system informasi desa berbasis web (studi kasus desa weding) dapat dilihat di URL : www.weding.web.id

\section{Daftar Pustaka}

Dien Novita. 2014."Faktor-Faktor Penghambat Pengembangan E-Government: Studi Kasus Pemerintah Kota Palembang, Sumatera Selatan", Jurnal Eksplora Informatika Vol. 4, No. 1, pp. 43-52, September 2014.

Effendi, Sofian. 2009. "Agenda Reformasi Birokrasi Pemerintahan Yang Responsif, Efisien, Efektif", Makalah pada Seminar Nasional Reformasi Birokrasi, Jakarta.

Jogiyanto, 2003," Sistem Teknologi Informasi”, Yogyakarta : Andi Offset.

Naba, Agus. 2009."Tutorial Cepat dan mudah Fuzzy logic dengan Matlab".Yogyakarta:Agus Naba

Novianti, F., Setiadi, T., Wahyuningsi, L., 2014, Implementasi Sikades (Sistem Informasi Kependudukan Desa) Untuk Kemudahan Layanan Administrasi Desa Berbasis Web Mobile, Jurnal lnformatika Universitas Ahmad Dahlan Yogyakarta.

Rotikan, R. dan Tamboto, C., 2016, Sistem Informasi Kependudukan Desa Maumbi, Seminar Nasional Teknologi Informasi Dan Multimedia STMIK AMIKOM Yogyakarta. 


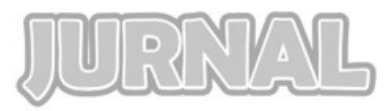

TEKNOLOGI INFORMASI DAN KOMUNIKASI 